\title{
Título da página electrónica: Portal de Cultura da
} UE

Endereço: www.europa.eu.int/comm/culture/

Paulo Peixoto

\section{(Q) OpenEdition}

\section{Journals}

Edição electrónica

URL: http://journals.openedition.org/rccs/1129

DOI: $10.4000 /$ rccs. 1129

ISSN: 2182-7435

\section{Editora}

Centro de Estudos Sociais da Universidade de Coimbra

Edição impressa

Data de publição: 1 dezembro 2003

Paginação: 146

ISSN: 0254-1106

\section{Refêrencia eletrónica}

Paulo Peixoto, "Título da página electrónica: Portal de Cultura da UE », Revista Crítica de Ciências Sociais [Online], 67 | 2003, posto online no dia 01 outubro 2012, consultado o 22 setembro 2020. URL : http://journals.openedition.org/rccs/1129; DOI : https://doi.org/10.4000/rccs.1129 


\section{Espaço Virtual}

\section{Título da página electrónica: Center for Arts \& Culture (EUA) Endereço: www.culturalpolicy.org/}

Criado em 1994, o Center for Arts \& Culture é uma organização não governamental constituída por várias comissões que realizam trabalho de pesquisa, de organização de seminários e de edição de publicações no domínio das artes e da cultura. Os recursos disponibilizados na página electrónica da instituição incluem, para além da informação e da investigação produzidas no próprio centro, notícias actuais, eventos, publicações e questões relativas às políticas culturais. Estes recursos repartem-se por sete áreas críticas das políticas culturais: o direito, a globalização, o acesso à cultura e às artes, a preservação, a comunidade, os investimentos e a educação.
A página, possuindo um design atractivo, é bastante intuitiva e de fácil navegação. Dispõe de um serviço de subscrição para os interessados em receber novidades e faculta a pesquisa num fundo bibliográfico que tem origem num observatório que reúne artigos, livros e apresentações e que pode ser pesquisado por autor, título ou assunto. Contudo, esta ferramenta não é fácil de localizar na página, estando acessível através da história do Centro. Por outro lado, quando se entra em cada uma das áreas, na barra do lado direito, que fornece informação adicional, o tamanho dos caracteres é excessivamente pequeno dificultando a navegação.

\section{Título da página electrónica: Comedia: creative thinking about cities and culture (UK) Endereço: http://www.comedia.org.uk/}

Reunindo alguns nomes sonantes da análise das políticas e da cultura urbanas (Charles Landry, François Matarasso, Phil Wood e Fred Brookes, como membros fundadores e, entre outros, Franco Bianchini e Peter Hall, como associados), a Comedia é, sem dúvida, uma das organizações que mais importantes meios disponibiliza para quem investiga ou desenvolve uma actividade profissional no campo da cultura e das artes.
A extensão org. do URL elide uma das mais significativas dimensões desta organização: a sua orientação para o mercado. As publicações que edita e os documentos que produz, alguns dos quais acessíveis por via electrónica, bem como as intervenções que promove e coordena no domínio das políticas culturais, são referências incontornáveis no campo da cultura e das políticas urbanas. Deve acrescentar-se a esta lista de recursos as interessantes ligações que faculta. 


\section{Título da página electrónica: Management of Social Transformations Programme - MOST Endereço: http://www.unesco.org/most/}

O MOST (Management of Social Transformations Programme) é um programa da UNESCO, criado em 1994, destinado a promover a investigação sobre as transformações globais contemporâneas. O MOST é coordenado pelo Secretariado da UNESCO em Paris, é dirigido por um Conselho intergovernamental, apoiado por um Conselho consultivo independente e desenvolve as suas actividades através de Comités nacionais MOST espalhados por 59 países.

O programa visa, particularmente, o estabelecimento de laços sustentáveis entre os investigadores das ciências sociais e os decisores políticos; o reforço das competências científicas, profissionais e institucionais, nomeadamente dos países em vias de desenvolvimento; e o estímulo à concepção de políticas de investigação localmente ancoradas. Os projectos e actividades que promove centram-se no estudo das sociedades multiculturais e multi-étnicas, assim como nas questões do desenvolvimento urbano, da globalização e da governação. Entre as funcionalidades que esta página oferece destacam-se a iniciativa "Forum MOST”, mantida em colaboração com a Sociological Research Online. Esta iniciativa permite o acesso a recursos variados e interessantes, como publicações, portais especializados em questões afins às preocupações do programa e à sociologia, ou recensões de livros. A estes recursos há que acrescentar outros igualmente relevantes: as publicações produzidas no âmbito do programa e de iniciativas laterais, sendo que nem todas estão publicadas na página; e um conjunto de bases de dados, composto por uma base de estudos de casos destinada a funcionar como manual de práticas exemplares nos domínios de actuação do MOST, e por duas bases constituídas a partir da análise das sociedades multiculturais, que compilam, quer direitos linguísticos, quer direitos religiosos.

\section{Título da página electrónica: Manchester Institute for Popular Culture (UK) Endereço: http://www.mipc.mmu.ac.uk/}

O Manchester Institute for Popular Culture é uma unidade de pesquisa multidisciplinar que promove investigação na área da cultura urbana.

Uma das áreas de pesquisa mais dinâmica reforça aquela que é talvez a imagem internacional que a cidade do norte de Inglaterra projecta actualmente: a pátria do futebol e a cidade de um dos clubes mundialmente mais conhecidos e bem sucedidos. Uma parte dos artigos produzidos neste centro de investigação não são virtualmente acessíveis, mas na secção downloads podem ser descarregados artigos sobre desporto e indústrias culturais. Já os arti- gos produzidos na área dos estudos culturais urbanos não estão acessíveis.

O forum sobre as indústrias culturais é um dos projectos interessantes que esta unidade tem presentemente em curso. Este forum tem servido para debater algumas questões pertinentes no campo da cultura, como, por exemplo, "o papel das indústrias criativas no combate à exclusão social"; "a função messiânica da cultura enquanto elemento que nos pode salvar dos males que afectam a civilização e as cidades"; ou o "potencial criativo das minorias no domínio da renovação da cultura urbana”. 


\section{Título da página electrónica: Ministère de la Culture et de la Communica- tion (França) \\ Endereço: www.culture.gouv.fr}

A página do Ministério da Cultura e da Comunicação francês é o reflexo da importância que a França, pelo menos desde que André Malraux ocupou a pasta da Cultura, concede a este sector. E se o país se apresenta e é visto em vários meios como a pátria da cultura, a página da instituição que tutela a cultura, as artes e a comunicação é, sem dúvida, um espelho que reflecte e amplia essa imagem.

Disponibilizando uma informação actualizada, variada e rica, esta página é uma referência obrigatória para quem, do plano artístico ao plano da investigação, passando pelo plano da prática cultural, se move no mundo da cultura.

Entre os múltiplos recursos acessíveis através desta página, contam-se alguns aspectos que merecem ser destacados: a mais de meia centena de bases de dados a que permite aceder (organizadas por 8 categorias: arquitectura e património; arquivos; cinema; língua francesa; livros e leitura; museus; música, dança e teatro; política cultural; e sócio-economia da cultura); as fontes e dados estatísticos que faculta; o minucioso recenseamento e a difusão de eventos culturais; a inventariação virtual dos espólios e colecções; as próprias exposições virtuais que organiza com uma qualidade audiovisual assinalável e uma informação detalhada no domínio do catálogo; a difusão de apoios de diferente natureza à profissionalização na área da cultura. Julgamos ser merecedora de um destaque especial a secção de "fichas práticas", onde podem ser recolhidos ensinamentos empíricos sobre, entre muitos outros aspectos, "como elaborar um projecto cultural"; "como se tornar um músico de intervenção"; "como utilizar as ajudas comunitárias", etc.

\section{Título da página electrónica: National Endowment for the Arts (EUA) Endereço: www.arts.endow.gov}

O slogan desta agência independente do Governo Federal dos EUA, "uma grande nação merece uma grande arte", ganha, desde logo, eco no carácter gráfico muito apelativo da página da organização, que merece um lugar de destaque na arte de bem construir páginas electrónicas. Mas este slogan encerra uma outra dimensão, que remete para o objectivo maior da existência desta organização: o de democratizar o acesso à cultura, permitindo o seu acesso a todos os cidadãos dos EUA.

O maior financiador da cultura nos EUA viu recentemente serem-lhe aplicadas reduções significativas no seu orçamento, o que originou a eliminação de alguns dos programas internacionais que projectavam a organização fora do seu país de origem. Ainda assim, o National Endowmwnt for the Arts continua a ser, entre as organizações nacionais que tutelam a cultura, aquela que maior protagonismo assume no apoio à exportação da criação cultural e artística que ocorre no interior das suas fronteiras.

A página tem, sobretudo, uma natureza informativa, não dispondo de conteúdos significativos noutras áreas que não a informativa. Ainda assim, estão acessíveis vários relatórios de pesquisa listados por 4 categorias: artistas; organizações; públicos e impacto económico. 


\section{Título da página electrónica: Organisation des Villes Patrimoine Mondial Endereço: www.ovpm.org}

A Organização das Cidades Património Mundial foi fundada em 1993 e reúne mais de 200 cidades que, no seu território, contam com pelo menos um bem incluído na lista do património mundial da UNESCO. A organização está sediada no Quebeque e as suas acções passam por difundir informações relacionadas com a aplicação da Convenção do Património Mundial, pela formação de gestores municipais, pela organização de debates e colóquios, pela intermediação junto das agências multilaterais que podem ajudar ao desenvolvimento das cidades-mem- bro, visando, ainda, implantar uma rede de comunicação electrónica e a construção de uma base de dados entre as cidades-membro.

A página electrónica da organização está disponível em 3 línguas (francês, inglês e castelhano).

Entre os recursos que disponibiliza salientam-se o acesso à vasta documentação internacional relativa à protecção do património, o guia de gestão para cidades históricas e o inventário das possíveis fontes de financiamento de acções de intervenção no património urbano.

\section{Título da página electrónica: Portal de Cultura da UE Endereço: www.europa.eu.int/comm/culture/}

Um espaço virtual voltado para a análise da cultura não podia deixar de fora a página de um projecto que, sendo também cultural, edifica uma instituição, no caso a União Europeia, que estrutura indelevelmente a actividade cultural nos países que a integram, quer financiando actividades, quer promovendo a mobilidade de artistas e iniciativas e bens culturais, quer ainda apoiando a formação de novos criadores ou enquadrando juridicamente as actividades culturais.

São 9 as áreas da cultura em que a União Europeia estrutura a sua actuação: a arquitectura; as artes visuais; o cinema e o audiovi- sual; a dança; a educação e a formação artísticas; o livro; a música; o património; e o teatro. Para cada uma destas áreas, a página divulga as medidas adoptadas pela União Europeia nas formas de apoio à cultura. A página, consultável em 5 línguas, não sendo o português uma delas, disponibiliza informação detalhada sobre uma das iniciativas mais marcantes e mais conhecidas da União Europeia no campo cultural: as Capitais Europeias da Cultura. Em termos de projectos futuros, um dos mais ambiciosos visados pela União Europeia é a criação de um observatório europeu da cooperação cultural.

\section{Título da página electrónica: Sustainable Cities Research Institute (UK) Endereço: www.sustainable-cities.org.uk/}

Este centro de investigação e de consultoria desenvolve a sua actividade numa área vital para a organização urbana dos nos- sos dias. O anuário da organização é uma ferramenta indispensável, não só para se ter conhecimento das actividades por ela 
desenvolvidas, mas também para se poder fazer o acompanhamento das iniciativas europeias nesta área.

As experiências em curso ao nível da gestão urbana, quer as que têm a ver com o emprego de novas tecnologias, quer com energias renováveis, quer ainda com novas práticas culturais, dão uma ideia clara do espectro de iniciativas em curso nas cidades onde estas preocupações se tornaram uma prioridade. É, contudo, pena que a página electrónica não disponibilize publicações e documentos que, nesta área, se constituem como os textos fundadores que motivam as preocupações com a sustentabilidade.

Paulo Peixoto 